Rajithan, M., Soorige, D. and Amarasinghe, S.D.I.A., 2021. Analysing the gap between predicted and actual operational energy consumption in buildings: A review. In: Sandanayake, Y.G., Gunatilake, S. and Waidyasekara, K.G.A.S. (eds). Proceedings of the $9^{\text {th }}$ World Construction Symposium, 9-10 July 2021, Sri Lanka. [Online]. pp. 63-74. DOI: https://doi.org/10.31705/WCS.2021.6. Available from: https://ciobwcs.com/papers/

\title{
ANALYSING THE GAP BETWEEN PREDICTED AND ACTUAL OPERATIONAL ENERGY CONSUMPTION IN BUILDINGS: A REVIEW
}

\author{
M. Rajithan ${ }^{1}$, D. Soorige ${ }^{2}$ and S.D.I.A. Amarasinghe ${ }^{3}$
}

\begin{abstract}
Operational energy consumption in buildings has a crucial impact on global energy consumption. Nevertheless, significant energy savings can be achieved in buildings if properly designed, constructed, and operated. Building Energy Simulation (BES) plays a vital role in the design and optimisation of buildings. BES is used to compare the costeffectiveness of energy-conservation measures in the design stage and assess various performance optimisation measures during the operational phase. However, there is a significant 'performance gap' between the predicted and the actual energy performance of buildings. This gap has reduced the trust and application of the BES. This article focused on investigating BES, reasons that lead to a performance gap between predicted and actual operational energy consumption of buildings, and the ways of minimising the gap. The article employed a comprehensive literature review as the research methodology. Findings revealed that reasons such as limited understanding of the building design, the complexity of the building design, poor commissioning, occupants' behaviour, etc., influence the energy performance gap. After that, the strategies have been identified to minimise the energy performance gap such as proper commissioning, creating general models to observe occupants' behaviour in buildings, and using the general models for energy simulation, ensuring better construction and quality through training and education, etc. Further, the findings of this study could be implemented by practitioners in the construction industry to effectively use energy simulation applications in designing energy-efficient and sustainable buildings.
\end{abstract}

Keywords: Building Energy Simulation (BES); Building sector; Operational Energy $(O E)$

\section{INTRODUCTION}

Buildings play an important role in consuming a large share of global energy consumption (Fan and Xiao, 2017). A building's Life Cycle Energy (LCE) comprises embodied energy (EE) and Operational Energy (OE). Energy spent for the construction of buildings, including transportation is known as embodied energy, and energy use by building services is known as OE (Praseeda et al., 2016). Stephan and Stephan (2016) stated that operational energy in buildings is the core energy consumption mode throughout the total

\footnotetext{
${ }^{1}$ Department of Building Economics, University of Moratuwa, Sri Lanka, rajimahen12@gmail.com

2 Department of Building Economics, University of Moratuwa, Sri Lanka, sooriged@uom.lk

${ }^{3}$ Department of Building Economics, University of Moratuwa, Sri Lanka, isuria@uom.lk
} 
lifetime of buildings. The energy consumed by the building during its use phase accounts for $80 \%-90 \%$ of the energy consumption of the entire life cycle (Brady and Abdellatif, 2017). According to Liu and Mi (2017), the operational energy of a building is mainly consumed by air conditioning, ventilation, lighting, and water distribution systems. Furthermore, in most buildings, the energy consumption of Heating Ventilation and Air conditioning (HVAC) systems make up 52\%, and lighting accounts for $25 \%$ of total operational energy consumption (Pérez-Lombard et al., 2008). Further, there are other factors that contribute to the use of energy during the operation phase of a building. The occupants' careless activities have a significant impact on the energy consumption. For instance, the occupants habitually tend to keep windows and doors open waste energy by creating an additional load on the HVAC system. This may result in an increase of three and a half times more energy utility for the HVAC system when compared to its regular consumption (Lee and Yang, 2017). The aging of equipment, defects in components and systems, and ineffective practices in buildings also cause energy wastages (Fan and Xiao, 2017). Further, an increase in population, changes in lifestyle, improvement in facilities, and duration of occupation in buildings impact the energy consumption of a building. (Pérez-Lombard et al., 2008). Considering the thermal comfort, increasing the comfort level of the buildings elevates energy usage by $20 \%$, and the hours of use of air conditioning has contributed to increasing the energy usage by $42-68 \%$ in similar weather conditions (Mastrucci and Rao, 2017).

Compared to other costs, the operational energy cost of the buildings is considerably high. Reducing the cost of energy in the operation phase significantly increases net profit. Therefore, it is necessary to plan at the initial stages of a building lifecycle to reduce the energy consumption during the operation phase. Energy simulation is a perfect and essential tool to measure and predict the operational performance at the design stage of a building to eliminate possible shortcomings during its use phase. Further, BES enables facility managers to analyse buildings' energy usage whilst optimising the performance (Cong et al., 2009). There are many energy simulation software such as Ecotect, eQuest, IES-VE, Design Builder, OpenStudio, ArchiCad 16, and EnergyPlus (Jarić et al., 2013). BES tools have been combined with modern technology and calculated energy consumption based on the parameters of the internal environment to predict the impact of the building's urban environmental energy demand (Gobakis and Koolokotsa, 2017). According to Hong et al. (2017), BES is widely used to forecast future energy utilisation and reduce energy wastage by implementing the necessary modifications. BES produces sound output through receiving input of energy utility information and other required parameters on energy consumption. BES is a tool used to measure the effect of the internal environment regarding the utility of energy in the building (Gobakis and Kolokotsa, 2017). Further, BES tools could also be used to view the energy performance changes before and after modifications are done (Zoras et al., 2017). BES tools help determine energy performance and find the possible advantages and mechanisms that help with energy savings and cost reductions (Ciampi et al., 2015).

However, Van Dronkelaar et al. (2016) mentioned that simulated energy prediction varies from actual energy consumption. Further, Hong et al. (2018), Turner and Frankel (2008), and Soebarto and Williamson (2001) agreed that variation in predicted and measured energy is a barrier to promote BES tools. Hence, to enable the use of BES tools, the gap should be identified and minimised. Less work has been devoted to exploring the factors 
that cause the gap between predicted and actual operational energy consumption of buildings, and these set the research agenda for the future. In this sense, an academic gap exists in recognising and analysing factors that cause the gap between predicted and actual operational energy consumption of buildings. Therefore, this study explores the factors that cause the gap between predicted and actual operational energy consumption of buildings. The study also identifies strategies to reduce the gap between predicted energy and actual energy consumption of buildings.

\section{RESEARCH METHODOLOGY}

As mentioned by Uyangoda (2010), a literature review is an important assessment conducted by researchers, to search for existing knowledge in the relevant problem domain. It enables the researcher to identify gaps with relevant evidence through the knowledge that is currently prevailing. Therefore, as in any research carried out, a sound literature review enriches and strengthens the research process. Hence, this study employed a comprehensive literature review to investigate the BES concept, factors that create a gap between predicted and actual operational energy consumption of buildings, and the ways of minimising the gap. The relevant literature was searched using search engines and data bases limited to 'Google Scholar', 'Scopus', 'Science direct' and 'Emerald'. When searching, 'OPERATIONAL ENERGY AND BUILDINGS', 'ENERGY SIMULATION AND BUILDING SECTOR', and 'SIMULATED ENERGY AND ACTUAL OPERATIONAL ENERGY CONSUMPTION' were used as the keywords to find the relevant publications for the research problem. Accordingly, around 55 peer-reviewed articles published between 2000-2020 were reviewed in this study. In addition, book chapters, conference proceedings, and publicly available publications were reviewed to gain a broader understanding of the area. Even though there are some steps of the systematic literature reviews integrated into this literature search, still it is identified as a conventional "comprehensive literature review". This is due to not following the formal systematic review protocols in this study to comply as a systematic literature review. In line with the review study conducted by Rathnayake et al. (2020), the steps shown in Figure 1 are conducted to perform the comprehensive literature review.

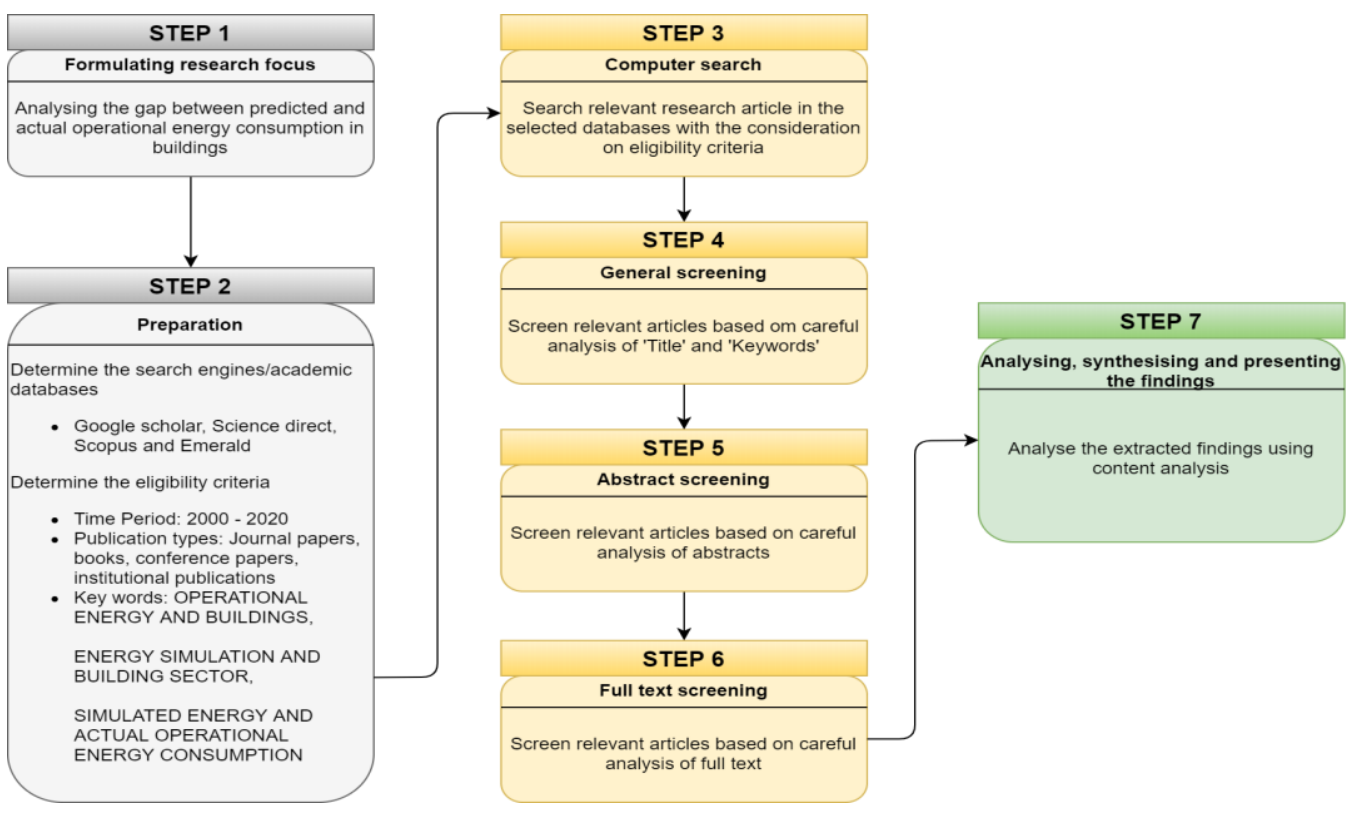

Figure 1: Research process (Adapted from: Rathnayake et al., 2020) 


\section{LITERATURE REVIEW}

\subsection{OPERATIONAL ENERGY AND BUILDINGS}

According to Devi and Palaniappan (2014), OE is the energy required for building operation during its use phase. Furtherm, Rasmussen et al. (2018) defined operational energy as the energy needed to maintain comfortable conditions in the building through processes such as heating, ventilation, air conditioning, hot water supply, and lighting. Further, according to Giordano et al. (2015), OE refers to Primary Energy Demand (PED) for heating, ventilation, cooling, hot water production, and lighting. Ramesh et al. (2010) stated that the OE of the building accounted for 80-90\% of total energy consumed by the building.

Air conditioning and illumination are the primary consumers of operational energy (Praseeda et al., 2016). Air conditioning uses 50\% of operational energy in buildings in the developed nations (Pérez-Lombard et al., 2008). Mastrucci and Rao (2017) stated that energy consumption for heating associated with the countries with cold climatic conditions accounts for around 25-36\% of the OE. The illumination occupied around 6$13 \%$ of OE. China is now the world's largest consumer of energy, the largest producer and consumer in 2019. According to the statistics of Building Research Establishment (BRE) and the Institute for the Diversification and Saving of Energy (IDEA), the energy composition of end uses in buildings is compared in three countries viz, United States of America (USA), United Kingdom (UK), and Spain. The comparison has been drawn based on the building facilities such as HVAC, lightings, equipment, Domestic Hot Water (DHW), refrigeration, food preparation, and others. In all three countries, HVAC accounted for the highest percentage, whilst lighting is placed as the second. Food preparation comes as the lowest percentage of total energy consumption in offices. The statistics of BRE and IDEA are presented in Table 1.

Table1: Operational energy composition of buildings in the USA, UK, and Spain

\begin{tabular}{lccc}
\hline \multicolumn{1}{c}{ Energy end uses } & USA (\%) & UK (\%) & Spain (\%) \\
\hline HVAC & 48 & 55 & 52 \\
Lighting & 22 & 17 & 33 \\
Equipment (appliances) & 13 & 5 & 10 \\
DHW & 4 & 10 & 0 \\
Food preparation & 1 & 5 & 0 \\
Refrigeration & 3 & 5 & 0 \\
Others & 10 & 4 & 5 \\
\hline
\end{tabular}

(Sources: Pérez-Lombard et al., 2008)

The OE in buildings is seen to have escalated with an increase in population, changes in lifestyle, improvement in facilities, and duration of occupation (Pérez-Lombard et al., 2008). Further, operational energy varies to a great extent with the level of comfort required, climatic conditions, and operating schedules (Ramesh et al., 2010). A 20\% increase in energy usage together with increasing hours of air conditioning usage to maximise the comfort level of the built environment has contributed to increasing the energy usage by $42-68 \%$ in similar weather conditions (Mastrucci and Rao, 2017). According to Kong et al. (2012), during the last 10 years, the energy use of the built 
environment has rapidly risen in China contributing to $30 \%$ of the total energy consumption of the country. Further, the energy consumption of the built environment in 2010 was twice as in 1996 due to the increase of the average annual rate by $10 \%$.

Overall, compared to other costs of buildings, the OE cost is a considerable amount. This reduction of the $\mathrm{OE}$ cost can greatly increase the net profit of the organisations. Therefore, it is necessary to control OE consumption. This can be planned from the early stages of the building's lifecycle. Considering such early interventions to reduce the OE, energy simulation can be identified as one of the best tools to evaluate changes in the built environment to meet varying requirements (Garwood et al., 2018). Further, the Building Energy Simulation (BES) is not only limited to the early phases of the building's lifecycle, there is room for energy efficiency improvements in the operation phase as well. The next section explains more details about BES.

\subsection{BUILDING ENERGY SiMULATION (BES)}

BES is also known as Building Energy Modelling (BEM) (Pang et al., 2016), Building Performance Simulation (BPS) (Kim and Park, 2016), or Building Energy Performance Simulation (BEPS) (Egan et al., 2018). BES applications for predicting building performance have been growing rapidly since the 1980s (Wright et al., 2013). BES provides several benefits for the users including prediction of the energy consumption of the buildings through the ever-increasing knowledge of information technology (Doukas et al., 2009; Mondrup et al., 2014), integrating standards to buildings (Doukas et al., 2009; Rallapalli, 2010), forecasting energy performance to facilitate decision-making (Garwood et al., 2018), estimation of the energy usage considering prevailing external conditions (Wang et al., 2018), verifying the accuracy of energy-related modifications in buildings (Murray et al., 2014) and supporting buildings designers such as architects and engineers to reduce energy consumption and cost (Abdullah et al., 2014).

BES software collects inputs from various sources and performs predictions at different phases of the building lifecycle (Abdullah et al., 2014). Energy simulation software plays a key role in reducing the cost of energy in buildings (Sousa, 2012). There are several energy simulation software such as DesignBuilder, EnergyPlus, eQuest, Green Building Studio, Integrated Environmental Solutions (IES), Sefaira, etc. (Sousa, 2012) with various interfaces for users by applying a variety of simulation engines (Abdullah et al., 2014). The software forecasts of the energy consumption include various parameters relating to energy in buildings such as the thermal condition, effect of air circulation and the use of natural ventilation, the energy consumption of equipment, and impact of the behaviour of occupants (Rallapalli, 2010). Further, according to Yi (2016), BES software also helps in using daylight in various places within the building that will help to minimise energy usage, improve the comfort of the workplace, and increase efficiency. For example, the use of current practices on illumination planning and power density are compared using energy simulation with standards, which can identify potential changes. Such changes in buildings reduce energy consumption, which leads to minimising operational costs (Delgoshaei et al., 2017). With the application of BES software, the HVAC load can be predicted throughout various seasons (Florentin et al., 2017). Consideration of climatic information using weather predictions has enabled us to weigh the effects of the external environment that contributes to the energy utilisation of the building (Gobakis and Kolokotsa, 2017). 
EnergyPlus is a freely available software, created by the United States Department of Energy to examine the performance of building services. EnergyPlus, simulation software comprehensively estimates energy loads of built environment such as heating and cooling and predicts energy consumption by providing the required parameters, which are necessary to verify predicted and real consumption. eQUEST was also created by the United States Department of Energy which has a less complex and user-friendly interface for energy evaluation to eliminate issues in Graphical User Interface (GUI). Sefaira is another commercial modelling software that supports the customers in creating a 3dimensional analysis of the model to examine the consumption of energy for HVAC. Further, the Sefaira application supports all architectural, engineering, or construction tools like Sketchup and Autodesk Revit. In addition, DesignBuilder is also a software that helps to produce 3-dimensional effective energy designs and operation models for buildings designed in a manner that can extract the required information from Building Information Modelling (BIM).

Van Dronkelaar et al. (2016) state that there is a difference between modeled energy prediction and the measured actual energy use in buildings. Further, Hong et al. (2018), Turner and Frankel (2008), and Soebarto and Williamson (2001) agree that variation in predicted and measured energy is a barrier to the acceptance of the BES tools for buildings. The next section explains the reasons identified in the literature for the gap in simulated energy and actual operational energy consumption in buildings.

\subsection{REASONS FOR THE GAP IN SIMULATEd AND ACTUAL OPERATIONAL ENERGY CONSUMPTION OF BUILDINGS}

According to Bordass et al. (2004), various causes lead to creating a gap in the predicted energy consumption using the BES and the actual energy consumption. A detailed review of the root causes for the energy performance gap is listed below which identified ten causes for the energy performance gap as given in the literature.

1. Lack of understanding about the building design

A lack of understanding with the professionals who do the BES regarding the design of the building, building orientation, materials used in construction, renewable energy sources used in building, etc. This would lead to errors in the energy simulation due to a lack of information or wrong information input to the BES software (Bucking et al., 2014).

2. The complexity of the building design

It has been identified a relationship of the complex building designs to increase the inaccuracies of the BES. The complex building designs seem to have more gaps in the predicted and actual energy performance than the more simple building designs (Bunn and Burman, 2015).

3. Uncertainties in building energy modeling

According to Kim and Augenbroe (2013), there are uncertainties in specifications and modelling such as numerical uncertainty, scenario uncertainty, the uncertainty of the assumptions, uncertainty of the building details, variations of materials, etc which lead to the gaps of the predicted and actual results. 


\section{Inter-model variability}

Raslan and Davies (2010) stated that there is 13 software that has been recognised for creating significantly wrong predictions for energy performance. Further, the modelling tools that are created by many countries for various purposes might not applicable for other situations. This results in varied predictions of the performance of a building in different countries.

\section{Poor on-site workmanship}

On-site workmanship needs to be adapted and training carried out to increase levels of complex building construction (Williamson, 2012). Installation of the drainage system, ducts for ventilation, and electrical conduit work will provide a means for gaps that negatively influence air tightness and also enable thermal loss (Morant, 2012). Such issues in the actual construction works create energy wastages that are not counted in the BES.

6. Changes after design

Morant (2012) reports poor compatibility between design specified and installed, which caused a significant effect on the divergence between predicted and actual data.

\section{Poor commissioning}

Buildings are handed over to clients after construction. There is a process of commissioning, a separate stage that ensures the building services such as HVAC, lighting, water supply systems, and other energy-using building systems meet with the owner's performance requirements and perform and operate as intended and at maximum energy efficiency (Wagner et al., 2007). Poor commissioning leads to create gaps in the predicted and actual energy consumption.

8. Poor practice and malfunctioning equipment

Assumptions made about temperature set points, control schedules, and the overall performance of the HVAC system, the actual operation of the building can be idealised from the design stage. However, in reality, many assumptions tend to deviate and directly affect the energy use of buildings during the operation phase.

\section{Occupants' behaviour}

Another dynamic factor during building operation is occupants. They have a substantial influence on the energy performance of a building by handling controls, such as those connected to lighting, sun shading, windows, set points, and office equipment, and also through their presence, and these controls may deviate from the predetermined schedule. BES might not be able to capture the impact of this complex behaviour of the occupants for energy consumption.

\section{Measurement system limitations}

Like the use of the building energy model to predict energy usage, the usage of metered energy through the measurement system should be verified to ensure the accuracy of the data. The limitations of the measurement system make the assessment of actual energy use inaccurate (Maile, 2010). 


\section{Longitudinal variability in operation}

The energy performance gap is generally assessed for a year of measured data. However, longitudinal performance is affected by factors such as building occupancy, deterioration of physical elements, climatic conditions, and building maintenance processes and policies (De Wilde et al., 2011).

As identified above, there is a considerable likelihood for the existence of gaps in the predicted and actual energy consumption due to such causes. The BES communities usually focus to mitigate or eliminate the causes of such gaps. The strategies to reduce the aforementioned gas are explained in the following section.

\subsection{STRATEGIES TO REDUCE THE GAP BETWEEN SIMULATION RESULTS AND ACTUAL ENERGY CONSUMPTION}

Literature has identified various strategies to reduce the gap between simulated and actual energy consumption. Ensuring proper hypothesis of prediction, perfect tuning of building services, and functioning of the facility as designed are important factors to monitor the simulation of the building. This has resulted, in the narrowing of the gap between actual energy consumption and estimated energy consumption (Vázquez et al., 2011). Further, Vázquez et al., 2011 mentioned that investigating and creating general models to observe the behaviour of tenants in buildings and using them in energy consumption prediction can reduce variations. Simple observation, obtaining readings, and generating a model to predict energy more absolutely, with the use of basic monitoring results will help to input the energy model with accuracy and predict the actual performance of the building (van den Brom et al., 2018; Gram-Hanssen and Georg, 2018). Furthermore, training and education are necessary to improve the skills of personnel in the construction industry by ensuring quality construction (Gram-Hanssen and Georg, 2018). Similarly, to strictly implement the maintenance and operation practices in the building, training, and education of facility managers should be strengthened. Whereas, in the design phase, energy modelers need to understand differences in energy performance, whilst promoting skills, innovation, and technological development to respond more appropriately in creating reliable designs. Post-occupancy evaluation can be properly conducted and it is resultant to minimise fine-tuning during operation and helps to reduce the gap between simulation results and actual energy consumption (Kimpian et al., 2014). In addition, Proper commissioning exercises can help maximise the efficiency of building services to avoid unnecessary energy use (Morant, 2012; Gram-Hanssen and Georg, 2018). Therefore, continuous monitoring of performance during operation is vital to ensure that the design goals are achieved under normal operating conditions (Torcellini et al., 2006). Further, continuous feedback can improve the design process and more accurately predict actual usage of energy performance (Hopfe and Hensen, 2011). Furthermore, model calibration aims to compensate for errors that may mask modelling errors at the entire building level (Clarke, 2001). Raftery et al. (2011) stressed that the calibration methods can improve the quality of future models by identifying common false assumptions and developing best-practice modelling methods. The reliability and accuracy of the calibration model depend on the quality of the measurement data used to create the model, as well as the accuracy and limitations of the tools used to simulate the building and its systems (Coakley et al., 2012). A summary of sections 3.3 and 3.4 is depicted in Figure 2. 


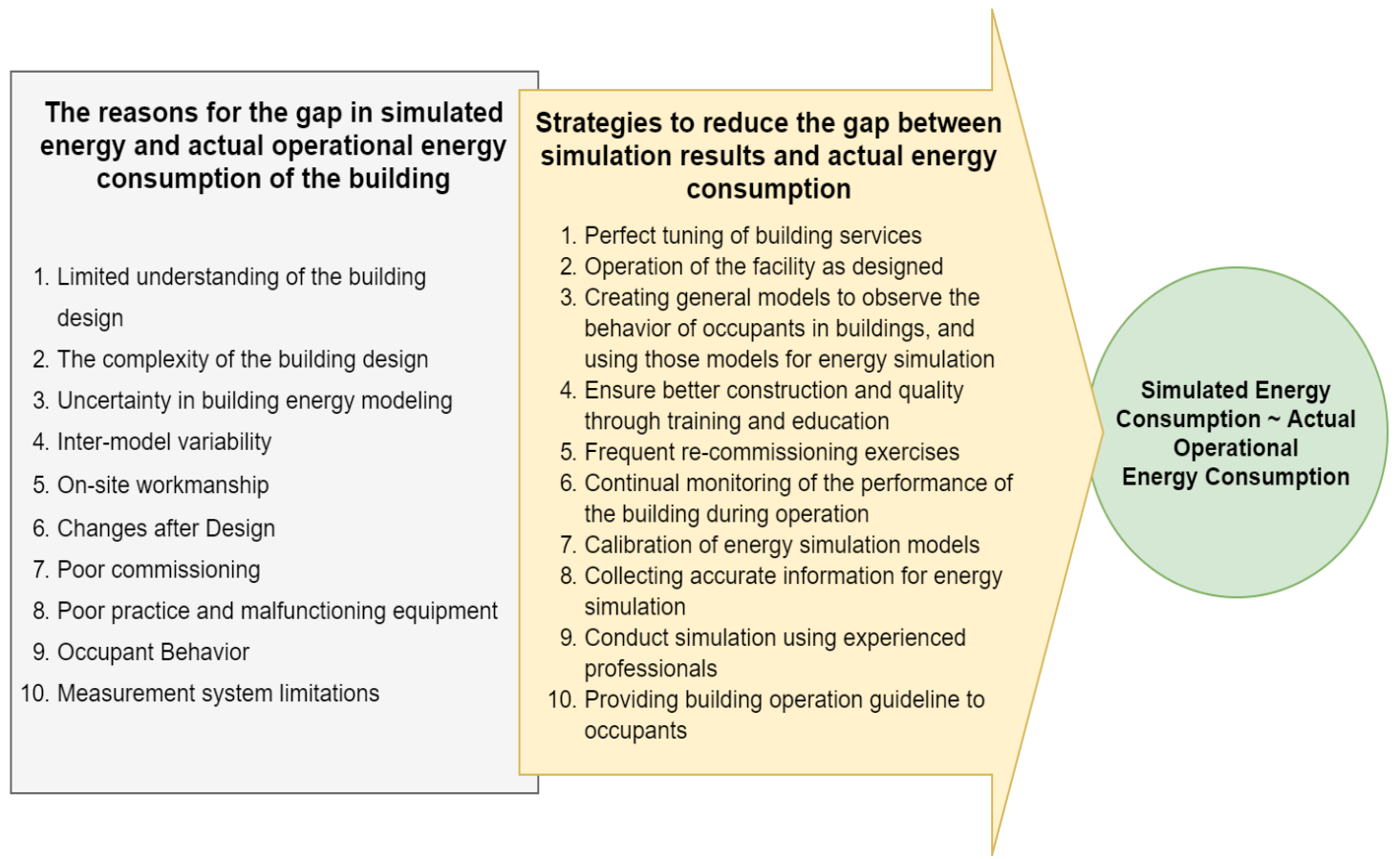

Figure 2: Summary of reasons for the energy performance gaps and strategies

\section{CONCLUSIONS AND THE WAY FORWARD}

This study provided an overview of the BES concept with respect to the gaps and strategies of the actual and predicted OE consumption. The building sector has been identified as one of the major contributors to the global environmental impact due to its high OE consumption. BES tools are important for building designers to reduce energy consumption and energy cost. The energy simulation software supports designers to take accurate decisions based on the simulation data. Therefore, the paper discusses the BES concept and its importance to the building sector and different types of BES tools. The literature highlighted that there is a significant gap between the predicted energy performance of buildings and the actual energy performance of buildings. Hence, reasons that created a gap between simulated energy and actual operational energy consumption of the building are discussed. Findings revealed that reasons such as limited understanding of the building design, the complexity of the building design, uncertainty in building energy modelling, poor commissioning, occupant behaviour, etc. negatively influence energy simulation. Thereafter, strategies such as proper commissioning, creating general models to observe the behaviour of tenants in buildings, and using those models for energy simulation, ensure better construction and quality through training and education, etc. are proposed to minimise the performance gap. Further, the findings of this study could be utilised by practitioners in the construction industry to use BES applications effectively for designing energy-efficient and sustainable buildings while minimising the predicted and actual energy performance gap. Further research can be carried out to determine the critical reasons which contribute to the gap between predicted and actual energy consumption. 


\section{REFERENCES}

Abdullah, A., Cross, B. and Aksamija, A., 2014. Whole building energy analysis: A comparative study of different simulation tools and applications in architectural design. In ACEEE Summer Study on Energy Efficiency in Buildings, pp. 1-12.

Bordass, B., 2004, April. Energy performance of non-domestic buildings: closing the credibility gap. In in Proceedings of the 2004 Improving Energy Efficiency of Commercial Buildings Conference.

Brady, L. and Abdellatif, M., 2017. Assessment of energy consumption in existing buildings. Energy and Buildings, 149, pp. 142-150.

Bucking, S., Zmeureanu, R. and Athienitis, A., 2014. A methodology for identifying the influence of design variations on building energy performance. Journal of Building Performance Simulation, 7(6), pp. 411426.

Bunn, R. and Burman, E., 2015, April. S-curves to model and visualise the energy performance gap between design and reality-first steps to a practical tool. Chartered Institution of Building Services Engineers (CIBSE).

Ciampi, G., Rosato, A., Scorpio, M. and Sibilio, S., 2015. Energy and economic evaluation of retrofit actions on an existing historical building in the south of Italy by using a dynamic simulation software. Energy Procedia, 78, pp. 741-746.

Clarke, J.A. and Clarke, J.A., 2001. Energy simulation in building design. Routledge.

Coakley, D., Raftery, P. and Molloy, P., 2012, September. Calibration of whole building energy simulation models: detailed case study of a naturally ventilated building using hourly measured data. In First building simulation and optimisation conference, pp. 57-64, Loughborough.

Cong, Z., Cahill, B. and Menzel, K., 2009. Analysis of energy simulation models. In Forum Bauinformatik, p. 37.

De Wilde, P., Tian, W. and Augenbroe, G., 2011. Longitudinal prediction of the operational energy use of buildings. Building and Environment, 46(8), pp.1670-1680.

Delgoshaei, P., Heidarinejad, M., Xu, K., Wentz, J.R., Delgoshaei, P. and Srebric, J., 2017, August. Impacts of building operational schedules and occupants on the lighting energy consumption patterns of an office space. In Building Simulation, Vol. 10, No. 4, pp. 447-458. Tsinghua University Press.

Devi, P. and Palaniappan, S., 2014. A case study on life cycle energy use of residential building in Southern India. Energy and Buildings, 80, pp. 247-259.

Doukas, H., Nychtis, C. and Psarras, J., 2009. Assessing energy-saving measures in buildings through an intelligent decision support model. Building and environment, 44(2), pp. 290-298.

Egan, J., Finn, D., Soares, P.H.D., Baumann, V.A.R., Aghamolaei, R., Beagon, P., Neu, O., Pallonetto, F. and O'Donnell, J., 2018. Definition of a useful minimal-set of accurately specified input data for Building Energy Performance Simulation. Energy and Buildings, 165, pp. 172-183.

Fan, C. and Xiao, F., 2017. Assessment of building operational performance using data mining techniques: a case study. Energy Procedia, 111, pp. 1070-1078.

Florentin, Y., Pearlmutter, D., Givoni, B., and Gal, E. (2017). A lifecycle energy and carbon analysis of hemp-lime bio-composite building materials. Energy and Buildings, 156, pp. 293-305.

Garwood, T.L., Hughes, B.R., Oates, M.R., O’Connor, D. and Hughes, R., 2018. A review of energy simulation tools for the manufacturing sector. Renewable and Sustainable Energy Reviews, 81, pp. 895911.

Giordano, R., Giovanardi, M., Guglielmo, G. and Micono, C., 2017. Embodied energy and operational energy evaluation in tall buildings according to different typologies of façade. Energy Procedia, 134, pp. 224-233.

Gobakis, K. and Kolokotsa, D., 2017. Coupling building energy simulation software with microclimatic simulation for the evaluation of the impact of urban outdoor conditions on the energy consumption and indoor environmental quality. Energy and Buildings, 157, pp. 101-115.

Gram-Hanssen, K. and Georg, S., 2018. Energy performance gaps: Promises, people, practices. Building Research \& Information, 46(1), pp. 1-9,

Hong, T., Kim, J., Jeong, J., Lee, M. and Ji, C., 2017. Automatic calibration model of a building energy simulation using optimisation algorithm. Energy Procedia, 105, pp. 3698-3704. 
Hong, T., Langevin, J. and Sun, K., 2018, October. Building simulation: Ten challenges. In Building Simulation (Vol. 11, No. 5, pp. 871-898). Springer: Berlin Heidelberg.

Hopfe, C.J. and Hensen, J.L., 2011. Uncertainty analysis in building performance simulation for design support. Energy and Buildings, 43(10), pp. 2798-2805.

Jarić, M., Budimir, N., Pejanović, M. and Svetel, I., 2013, June. A review of energy analysis simulation tools. In TQM 2013, Proceedings of $7^{\text {th }}$ International Working Conference of Total Quality Management-Advanced and Intelligent approaches. Belgrade: Mechanical Engineering Faculty, pp. 103-110.

Kim, S.H. and Augenbroe, G., 2013. Uncertainty in developing supervisory demand-side controls in buildings: A framework and guidance. Automation in Construction, 35, pp. 28-43.

Kim, Y.J. and Park, C.S., 2016. Stepwise deterministic and stochastic calibration of an energy simulation model for an existing building. Energy and Buildings, 133, pp. 455-468.

Kimpian, J., Burman, E., Bull, J., Paterson, G. and Mumovic, D., 2014. Getting real about energy use in non-domestic buildings. In CIBSE ASHRAE Technical Symposium.

Kong, X., Lu, S. and Wu, Y., 2012. A review of building energy efficiency in China during "Eleventh FiveYear Plan" period. Energy Policy, 41, pp. 624-635.

Lee, C. and Yang, H., 2017. A context-awareness system that uses a thermographic camera to monitor energy waste in buildings. Energy and Buildings, 135, pp. 148-155.

Liu, M.M. and Mi, B., 2017. Life cycle cost analysis of energy-efficient buildings subjected to earthquakes. Energy and Buildings, 154, pp. 581-589.

Maile, T., 2010. Comparing measured and simulated building energy performance data. Stanford University.

Mastrucci, A. and Rao, N.D., 2017. Decent housing in the developing world: Reducing lifecycle energy requirements. Energy and buildings, 152, pp. 629-642.

Mondrup, T.F., Karlshøj, J. and Vestergaard, F., 2014. Building Performance Simulation tools for planning of energy efficiency retrofits. In $10^{\text {th }}$ Nordic Symposium on Building Physics; Lund University: Lund, Sweden.

Morant, M., 2012. CEW1005: The performance gap: Nondomestic building: Final report.

Murray, S.N., Walsh, B.P., Kelliher, D. and O’Sullivan, D.T.J., 2014. Multi-variable optimisation of thermal energy efficiency retrofitting of buildings using static modelling and genetic algorithms - A case study. Building and Environment, 75, pp. 98-107.

Pang, X., Nouidui, T.S., Wetter, M., Fuller, D., Liao, A. and Haves, P., 2016. Building energy simulation in real time through an open standard interface. Energy and Buildings, 117, pp. 282-289.

Pérez-Lombard, L., Ortiz, J. and Pout, C., 2008. A review on buildings energy consumption information. Energy and buildings, 40(3), pp. 394-398.

Praseeda, K.I., Reddy, B.V. and Mani, M., 2016. Embodied and operational energy of urban residential buildings in India. Energy and buildings, 110, pp. 211-219.

Raftery, P., Keane, M. and O’Donnell, J., 2011. Calibrating whole building energy models: An evidencebased methodology. Energy and Buildings, 43(9), pp. 2356-2364.

Rallapalli, H.S., 2010. A comparison of EnergyPlus and eQUEST whole building energy simulation results for a medium sized office building (Doctoral dissertation, Arizona State University).

Ramesh, T., Prakash, R. and Shukla, K.K., 2010. Life cycle energy analysis of buildings: An overview. Energy and Buildings, 42(10), pp. 1592-1600.

Raslan, R. and Davies, M., 2010. Results variability in accredited building energy performance compliance demonstration software in the UK: an inter-model comparative study. Journal of Building Performance Simulation, 3(1), pp. 63-85.

Rasmussen, F.N., Malmqvist, T., Moncaster, A., Wiberg, A.H. and Birgisdóttir, H., 2018. Analysing methodological choices in calculations of embodied energy and GHG emissions from buildings. Energy and Buildings, 158, pp. 1487-1498.

Rathnayake. R.M.D.I.M., Sridarran. P. and Abeynayake. M.D.T.E, 2020, Total building performance mandates in building evaluation: a review Dimensions of Space - multi-disciplinary Approaches: 
Proceedings of the $13^{\text {th }}$ FARU International Research Conference (Faculty of Architecture Research Unit), University of Moratuwa, Sri Lanka, November 06-07, 2020, Colombo, pp. 150-157.

Soebarto, V.I. and Williamson, T.J., 2001. Multi-criteria assessment of building performance: theory and implementation. Building and environment, 36(6), pp. 681-690.

Sousa, J., 2012, September. Energy simulation software for buildings: review and comparison. In International Workshop on Information Technology for Energy Applicatons-IT4Energy, Lisbon.

Stephan, A. and Stephan, L., 2016. Life cycle energy and cost analysis of embodied, operational and usertransport energy reduction measures for residential buildings. Applied Energy, 161, pp. 445-464.

Torcellini, P., Pless, S., Deru, M., Griffith, B., Long, N. and Judkoff, R., 2006. Lessons learned from case studies of six high-performance buildings (No. NREL/TP-550-37542). National Renewable Energy Lab. (NREL), Golden, CO (United States).

Turner, C., Frankel, M. and Council, UGB, 2008. Energy performance of LEED for new construction buildings. New Buildings Institute, 4(4), pp. 1-42.

Uyangoda, J., 2010. Sri Lanka in 2009: From civil war to political uncertainties. Asian Survey, 50(1), pp. 104-111.

van den Brom, P., Meijer, A. and Visscher, H., 2018. Performance gaps in energy consumption: household groups and building characteristics. Building Research \& Information, 46(1), pp. 54-70.

Van Dronkelaar, C., Dowson, M., Burman, E., Spataru, C. and Mumovic, D., 2016. A review of the energy performance gap and its underlying causes in non-domestic buildings. Frontiers in Mechanical Engineering, 1, p. 17.

Vázquez, F.I., Gaceo, S.C., Kastner, W. and Morales, J.A.M., 2011. Behavioral profiles for building energy performance using exclusive som. In Engineering Applications of Neural Networks, pp. 31-40. Springer, Berlin, Heidelberg.

Wagner, A., Klebe, M. and Parker, C., 2007. Monitoring results of a naturally ventilated and passively cooled office building in Frankfurt, Germany. International Journal of Ventilation, 6(1), pp. 3-20.

Wang, L., Kubichek, R. and Zhou, X., 2018. Adaptive learning-based data-driven models for predicting hourly building energy use. Energy and Buildings, 159, pp. 454-461.

Williamson, B. and Currie-Director, J., 2012. The Gap between Design and Build: Construction Compliance towards 2020 in Scotland.

Wright, A.J., Oates, M.R. and Greenough, R., 2013. Concepts for dynamic modelling of energy-related flows in manufacturing. Applied Energy, 112, pp. 1342-1348.

Yi, Y.K., 2016. Adaptation of Kriging in daylight modelling for energy simulation. Energy and Buildings, 111, pp. 479-496.

Zoras, S., Veranoudis, S. and Dimoudi, A., 2017. Micro-climate adaptation of whole building energy simulation in large complexes. Energy and Buildings, 150, pp. 81-89. 